\title{
Influence of backfill soil shear strength parameters on retaining walls stability
}

\author{
Influencia de los parámetros de resistencia al corte del suelo de relleno sobre la \\ estabilidad de muros de contención
}

Luis A. Lemus (Main Author)

Departamento de Ingeniería Civil en Obras Civiles, Universidad de La Serena

Benavente 980, La Serena (Chile)

llemus@userena.cl

Nelson O. Moraga

Departamento de Ingeniería Mecánica, Universidad de La Serena

Benavente 980, La Serena (Chile)

nmoraga@userena.cl

Roberto Lemus-Mondaca (Corresponding Author)

Departamento de Ciencia de los Alimentos y Tecnología Química

Facultad de Ciencias Químicas y Farmacéuticas, Universidad de Chile

Santos Dumont 964, Independencia, Santiago (Chile)

rlemus@uchile.cl

Manuscript Code: 473

Date of Acceptance/Reception: 31.03.2017/31.08.2015

DOI: $10.7764 /$ RDLC.16.2.175

\section{Abstract}

One of the problem of geotechnical engineering is the analysis of the retaining walls stability, where are several uncertainty sources. Some of these uncertainties relate to the inherent variability of fill soil, retained by the retaining wall, strength parameters. This feature can be quantified through a retaining wall stability probabilistic analysis using the Monte Carlo Simulation method (SMC), which enables to determine the wall reliability from collected testing shear strength information of existing soils in the cities of Coquimbo and La Serena, Coquimbo Region, Chile. An application example, the study of a cantilever retaining wall stability filled with silty sand soil (SM) with three different degrees of compaction (DC\%: 80,90 and 95\%), with the objective to analyze the wall stability through statistical analysis of safety factors.

Key words: Retaining walls, Factor of safety, simulation, Monte Carlo method, reliability analysis.

\begin{abstract}
Resumen
Uno de los problemas de ingeniería geotécnica es el análisis de la estabilidad de muros de contención, en donde se presentan diversas fuentes de incertidumbre. Algunas de estas incertidumbres se relacionan con la variabilidad inherente de los parámetros de resistencia del suelo de relleno retenido por el muro de contención. Esta característica puede ser cuantificada a través de un análisis probabilístico de la estabilidad del muro de contención utilizando el método de Simulación de Monte Carlo (SMC), el que permite determinar la fiabilidad del muro a partir de información recolectada de ensayos de resistencia al corte de suelos existentes en las ciudades de Coquimbo y La Serena, región de Coquimbo, Chile. Un ejemplo de aplicación, se estudia la estabilidad de un muro de contención tipo Cantiléver con suelo de relleno arena limosa (SM) con tres distintos grados de compactación (DC\%: 80, 90 y 95\%), con el objetivo de analizar la estabilidad del muro a través del análisis estadístico de los factores de seguridad.
\end{abstract}

Palabras clave: Muro de contención, factores de seguridad, simulación, método de Monte Carlo, análisis de fiabilidad.

Introduction

It is essential for an engineer to count on tools to quantify the uncertainty of the models he is developing since they enable him to choose, based on his experience, the various factors he will use throughout his project. Calculation and the design of damming structures are included within the commonest engineering problems both for geotechnical and structural engineers, where the main difficulty takes root on determining the stability the wall has in case of a possible fault (Centeno, 2002). To determine a the stability of a retaining wall is necessary to assign the safety the wall has stability the retaining wall has to sliding and overturning occurrences- Those factors are related to the retaining wall geometry, overloads, static thrusts and sismic endurance, ground properties (Carillo \& Alcocer, 2011); but all of these safety factors do not allow to quantify 
the uncertainties of the variables being used. For instance, when determining the parameters inherent to the soil.

Soils are very changeable as to their features and a few times they are naturally homogenous One of the main source of diversity has to do with the inherent spatial of soils, the variation of features from a spot to another is related to different accumulation conditions and different tension condition owing to a historical overburden (Elkated \& Chalaturnyk, 2003). The reliability on soil factors to be considered for designs are affected by a series of uncertainties coming from the following sources: Inherent spatial variation, measurement errors, statistic errors and uncertainties on the geomechanical properties coming from laboratory test (Phoon \& Kulhawy, 1999). Spatial variation concerning soil properties can be correctly represented by statistic correlation from a field framework of contingent variables (Vanmarcke, 1977).

The Monte Carlo simulation Method is very useful to quantify the uncertainty in constructive process developments and to determine the parameters inherent to the soils. Owing to this reason a retaining wall analysis is performed by a Monte Carlo simulation, by using a base data of silty sands occurring in Coquimbo and La Serena Cities, Chile (Calderón, 2004). The objective of this work is meant to analyze walls retaining influence on the wall stability due to the variety of retaining parameters of a backfilling soil, In our case, we count on a silty sands as a data base having a 3 grades of compression for the highest dry compacted density (DC 85, 90 and 95\%).

\section{Retaining Wall stability concepts}

\section{Limit equilibrium behavior}

The stability of a retaining wall is commonly analyzed by using a limited equilibrium behavior, where a failure mechanism is generated on the soil or into structure itself (Zevgolis \& Bourdeau, 2010). To avoid such a failure, the condition is studied immediately before the fail is produced instead of the complete wall collapse. Furthermore, It is assumed that the retaining wall is classified as a rigid structure according to the soilstructure interaction where no important deformation previous an overload from the retained soil is present. This type of structure behaves as a rigid solid. Therefore, in this particular case the retaining wall analysis becomes conditioned to the soil parameters and not by the structure itself.

\section{Stable slope condition}

It belongs to the case that is normally analyzed in soil mechanic discipline. It is supposed that soil is homogeneous and the pressure generated from the soil is according to the theories by Rankine and Coulomb (Rankine \& Coulomb, 1976), where pressure soil coming both from static and sismic condition have a rectangular shaped distribution. To analyze retaining walls, the Coulomb and Mononobe-Okabe earth pressure methods are used, for static and sismic cases respectively (Okabe, 1926).

\section{External stability analysis}

Static analysis. The forces and earth pressures that are developed in this case are shown in Figure 1 . The forces are the wall weight $\left(W_{m}\right)$ and soil retained weight on the heel $\left(W_{s}\right)$; the friction force on the base of the foundation ( $\left.T_{\text {est }}\right)$; sliding forces upon the fictitious plane $A B\left(T_{e 2}\right.$ y $\left.T_{e 1}\right)$; permanent overload $\left(W_{q}\right)$ and soil static pressure including the overburden effect $q\left(E_{e}\right)$. 


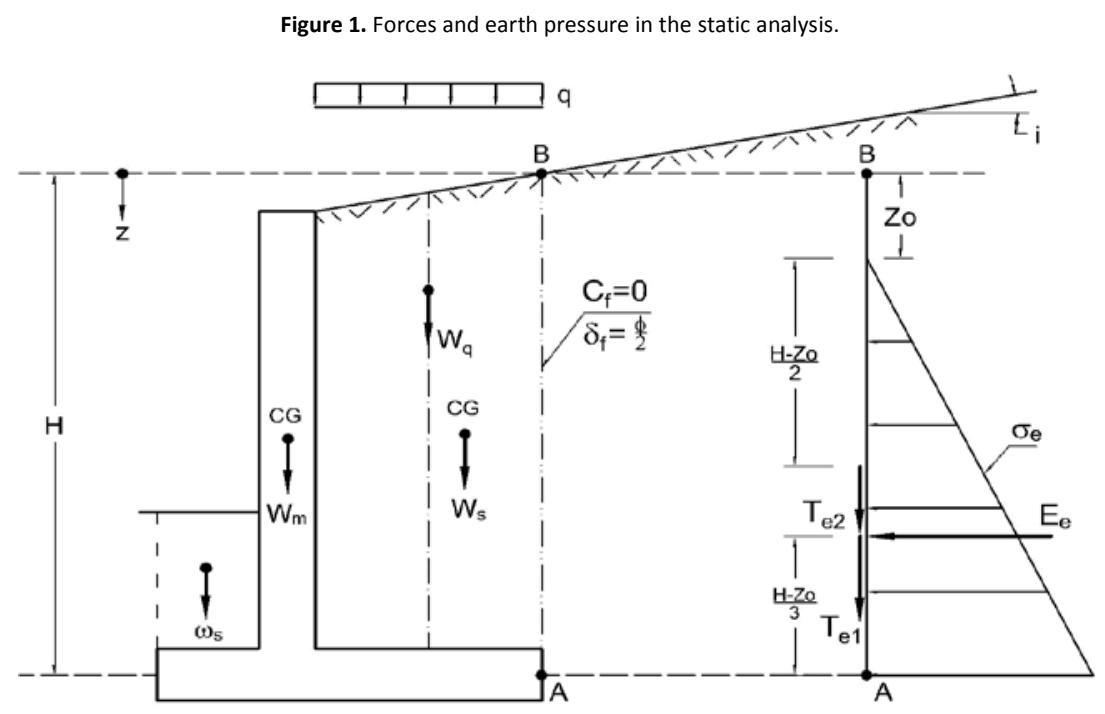

Sismic Analysis. For a sismic analysis the Chilean Rule NCh 433 Of.96 "Building's analysis design" (INN-Chile, 1996) Such an analysis takes into account both forces and pressure from the static case and are added to the soil sismic inertia forces $\left(\mathrm{C}_{\mathrm{s}}, \mathrm{W}_{\mathrm{m}}\right.$ and $\left.\mathrm{Cs} \mathrm{W}_{\mathrm{s}}\right)$, sismic soil pressure $\left(\mathrm{E}_{\mathrm{s}}\right)$ sismic friction strains $\left(T_{\text {sis }}, T_{s}\right.$ and $\left.T_{s q}\right)$ and sismic pressure owing to a permanent overload as it is shown in Figure 2.

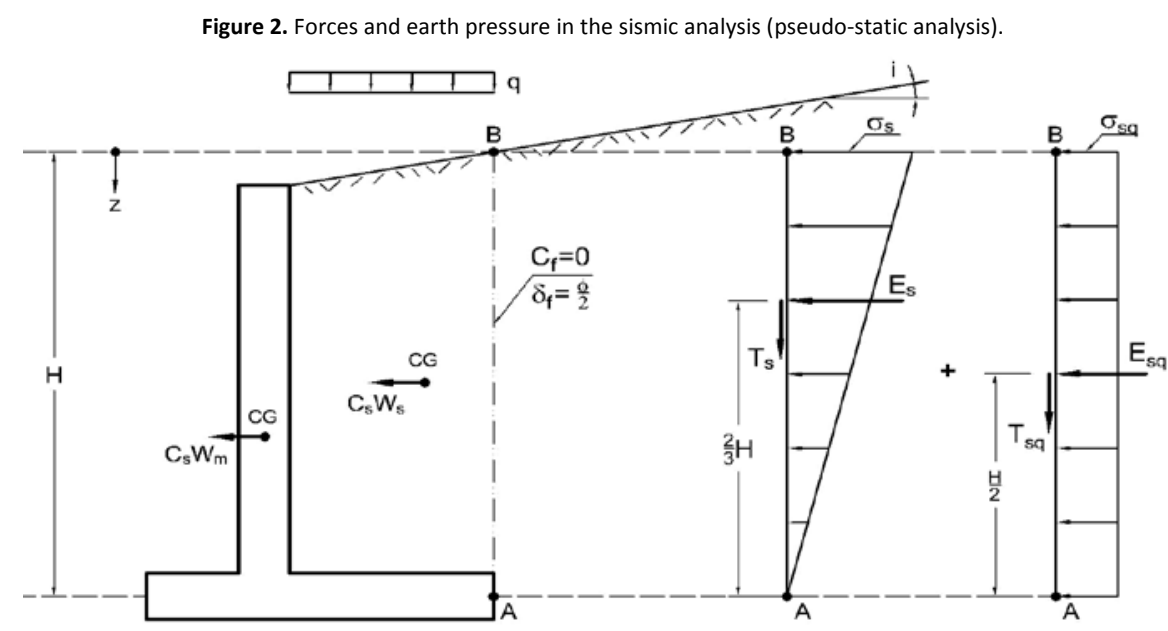

Process simulation

\section{Base model Identification}

To determine quantitatively the reliability of retaining wall, it has been determined that the system being studied to consider as their stability analysis which are simulated based upon soil filling data existing in La Serena and Coquimbo cities, these soils go together with muddy sands having a compression adding up to $3^{\circ}$ from the greatest dried compressed density (DC\%: 85, 90 and 95\%). The basic model is developed according to the judgement and requirements for the design of highways Manual to analyze and design the retaining wall (High way Service - Highroad manual, 2008) where the relationships determining static and sismic soil thrust are used. Within the model there is a great amount of variables influencing the calculation of the required and opposing forces of the system where soils filling parameters feature certain variables under the same compressing conditions $(8,10$ and $14 \%)$ and a percentage of fines $(8,10,14,15,17,18$ and $22 \%)$. In such a case, internal friction angle will be considered as the stochastic variable of the system. For the static analysis, the static thrust, water thrust, sliding friction of soil structure, filling soil weight, the weight from retaining and overload structure are considered. In the sismic case the static analysis is considered where the inertia sismic forces from filling soils and overloads are added. The variables from the models' rated output match with the 
safety factors for static and sismic. The fail develops in the model when one out of the four factor in lower than 1 , this mean that the retaining forces or moments are not able to endure the slipping forces and the overturning moments of the system. Next, the relationships representing the safety factors mentioned above:

Static safety factor when slipping:

$$
F S E D=\frac{F_{\text {resist }}^{\text {est }}}{F_{\text {solic }}^{\text {est }}}
$$

Static safety factor when overturning:

$$
F S E V=\frac{M_{\text {resist }}^{\text {est }}}{M_{\text {volc }}^{\text {est }}}
$$

Sismic safety factor when slipping:

$$
F S S D=\frac{F_{\text {resist }}^{\text {sis }}}{F_{\text {solic }}^{\text {sis }}}
$$

Sismic safety factor when overturning:

$$
F S S V=\frac{M_{r e s i s t}^{\text {sis }}}{M_{\text {volc }}^{\text {sis }}}
$$

Where: $F_{\text {resist }}:$ Sum of strong forces $(T o n / m l) ; F_{\text {solic }}:$ Sum of contender forces $(T o n / m l) ; M_{\text {resist }}$ : Sum of strong momentum (Ton-m/ml) and $M_{\text {solic }}$ : Sum of contender momentum (Ton-m/ml); $H$ is the wall height $(\mathrm{m})$.

\section{Data base obtainment}

Once stochastic variables were identified, it was proceeded to collection and database analysis form silty sands showing that the probability distribution having the best fitting to the variable behavior are both Normal and Lognormal distributions and these distributions are determined by calculating media and standard data deviation (Table 1). Then, histograms and probability fitting to the internal friction angle are shown as well as their compressing grades of 80,90 and $95 \%$ (Figure 3-5).

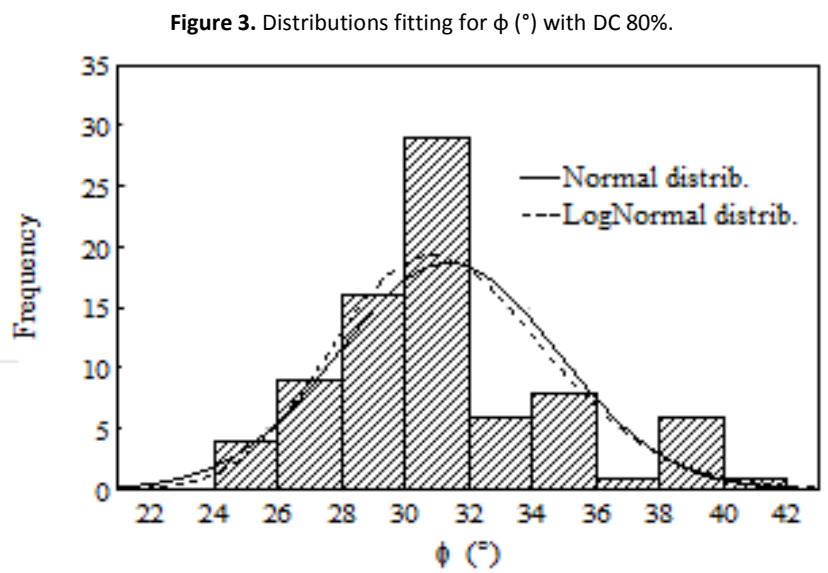

Figure 4. Distributions fitting for $\phi\left({ }^{\circ}\right)$ with DC $90 \%$.

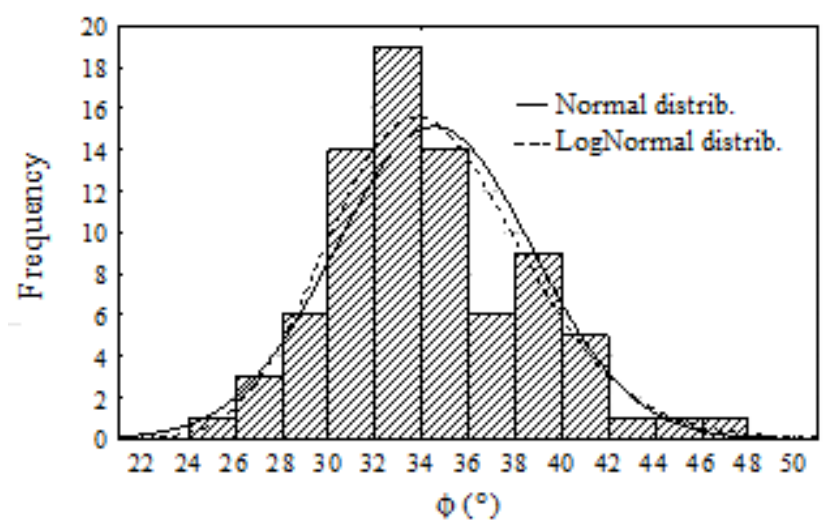




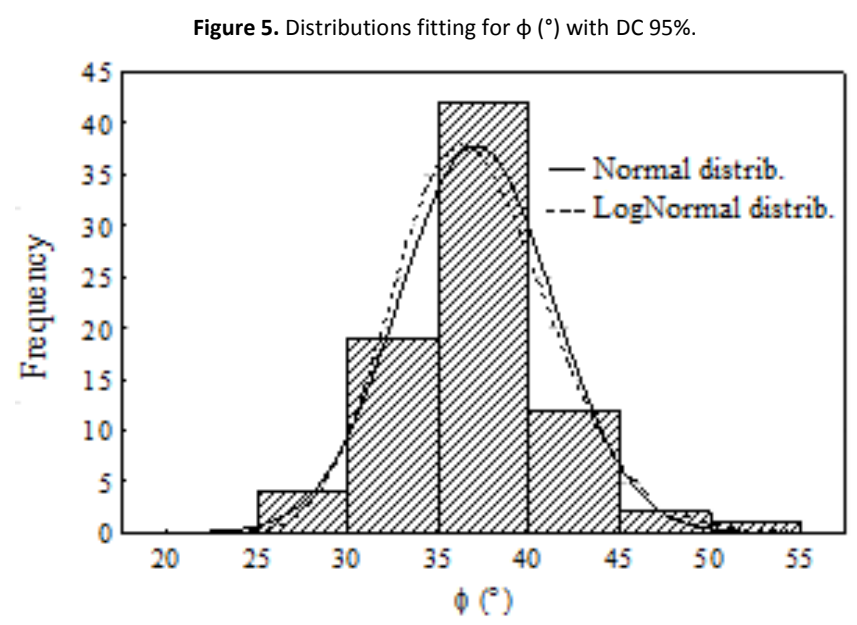

Table 1. Summary of distributions fitting for silty sand.

\begin{tabular}{cccccc}
\hline \multirow{2}{*}{$\% \mathrm{DC}$} & \multicolumn{2}{c}{ Normal Distribution } & & \multicolumn{2}{c}{ Lognormal Distribution } \\
\cline { 2 - 3 } \cline { 5 - 6 } & $\mu_{\phi}\left({ }^{\circ}\right)$ & $\sigma_{\phi}\left({ }^{\circ}\right)$ & & $\mu_{\lambda v \phi}$ & $\sigma_{\lambda v \phi}$ \\
\hline 80 & 31.30 & 3.42 & & 3.438 & 0.107 \\
90 & 34.35 & 4.22 & & 3.532 & 0.121 \\
95 & 36.96 & 4.22 & & 3.603 & 0.116 \\
\hline
\end{tabular}

Where: $\mu_{\phi}$ is the internal friction angle average for Normal distribution $\left({ }^{\circ}\right) ; \sigma_{\phi}$ is the internal friction angle standard deviation for Normal distribution $\left({ }^{\circ}\right) ; \mu_{\lambda v \phi}$ is the internal friction angle average for Lognormal distribution and $\sigma_{\lambda v \phi}$ is the internal friction angle standard deviation for Lognormal distribution.

\section{Probabilistic Analysis from retaining walls stability}

The focusing is proposed by the Monte Carlo Simulation (MCS) although it is costly form the calculation viewpoint it is an exact way to capture the variety effects that are inherent to the parameters of retaining soils (Popescu et al., 1998). The simulation is carried out by a Design Software and a retaining wall analysis by using both the Monte Carlo v.2 (González and Lemus, 2010), and a Visual basic 6.0 version. This Model's output variables are the static - sismic safety factors against sliding and overturning and based on these variables walls' stability could be quantified through its reliability. That's to say, it is possible to verify the probability of a fail from system influenced by the inherent variation from the retaining parameters of filling soils The simulation is based on the generation of pseudo-contingent numbers coming from a congruential algorithm (García et al., 2006) and a Randomize option included in the Visual Basic 6.0 that generates 30.000 top run sprints. Contingent Variables are obtained by Box-Müller Method that is described by equation 9 which generates normal stringent variables that are normal. To this probabilistic analysis, a dimension vector is developed " $n$ ", $X=\left[X_{1}, X_{2}, X_{3}, \ldots X_{n}\right]$ that represents an aleatory variable set. Then, from each randomize variable, the output variables are calculated, i.e. safety factor's vectors $\left(F S_{i}\right)$ for: FSED, FSEV, FSSD, FSSV, to subject them to a statistical analysis. It must be verified that each factor average is higher that $1\left(F S_{i}>1\right)$ to avoid a fail from system. Based on this condition the fail probability concept (PF) is used, such a concept is calculated by using the distribution of normal standard probability.

$P F=P\left(F S_{i}<1\right)$

Then the wall safety is determined $\left(F_{m}\right)$ by using equation:

$F_{m}=1-P F$

In short, the simulation process is performed by the following steps:

1. To develop pseudo- randomize numbers by using a congruential algorithm that consists of using randomize numbers between 0 and 1 by the following recursive formula. 
$x_{i+1}=\left(a \cdot x_{i}+b\right) \bmod m$

$U_{i}=\frac{x_{i}}{m}$

Where: PF is the failure probability (\%); $F_{m}$ is the wall reliability (\%); FS is the security factor; $a, b, m$ are the consistency algorithm coefficients.

The procedure to develop the course of pseudo-random numbers is the following: 1) Any "seed number" is chosen, preferably lower than 1000; 2 ) the module " $m$ " is chosen being represented by a high prime number; 3) A coefficient " $a$ " is selected, it has to end up in $01,21,41,61$ or 81 ; 4) An independent term is chosen " $b$ " ending in $1,3,5,7 \circ 9 ; 5)$ For the first pseudo-random number corresponding to $x_{0}$, it must be calculated $x_{0}=$ seed number and $\left.a \cdot x_{i}+b ; 6\right)$ The value of $\left(a \cdot x_{i}+b\right) \bmod m$ is calculated; 7$)$ the value that was found must be divided in the step 6 between " $\mathrm{m}$ " module where the first pseudo-random number comprised between 0 and 1 is obtained; 8 ) The value $\left(a \cdot x_{i}+b\right)$ mod $m$ obtained is used in the step 6 as a value $x_{i}$ and the second number is calculated by following the steps 5 and 7 , and 9) The procedure is repeated according to the number of series " $n$ " to obtain the required randomize numbers.

2. Generation of normal standard random variables base on the Box-Müller method (Box \& Müller, 1958):

$$
\begin{aligned}
& X_{1}=\left[\sqrt{-2 \ln \left(1-U_{1}\right)} \cdot \cos \left(2 \cdot \pi \cdot U_{2}\right)\right] \cdot \sigma+\mu \\
& Y_{1}=\left[\sqrt{-2 \ln \left(1-U_{1}\right)} \cdot \operatorname{sen}\left(2 \cdot \pi \cdot U_{2}\right)\right] \cdot \sigma+\mu \\
& N N=\frac{X_{1}+Y_{1}}{2}
\end{aligned}
$$

Where: $\mu$ is distribution average of date base; $\sigma$ : is distribution standard deviation of date base; $c v$ is the covariance of output variable; $X_{1} Y_{1}, N N$ : Randomize variables by Normal or Lognormal distribution; $U_{1} U_{2}$ : Independent pseudo-random numbers.

3. Output obtainment from variables and their statistic study.

4. Calculation of the probability of failure and reliability of the retaining wall.

It should be noted that the maximum number of runs accepted by the program is 30000 repetitions, which easily surpasses the optimal number of runs for the simulation, which is in the order of 4000 to 10000 repetitions, thus there is no problem regarding to stabilization of the variable to simulate.

\section{Application example}

The example consists of the study of a retaining wall from a cantilever type having a silty filling soil (Figure 1). Monte Carlo simulation is applied by using the software developed by Gonzales and Lemus (2010) (Figure 6). Where: $\phi$ is the internal friction angle of filling soil $\left({ }^{\circ}\right) ; \nu$ is the filling soil density $\left(\mathrm{Ton} / \mathrm{m}^{3}\right) ; c$ is the cohesion of the filling soil $\left(T o n / \mathrm{m}^{2}\right)$. 


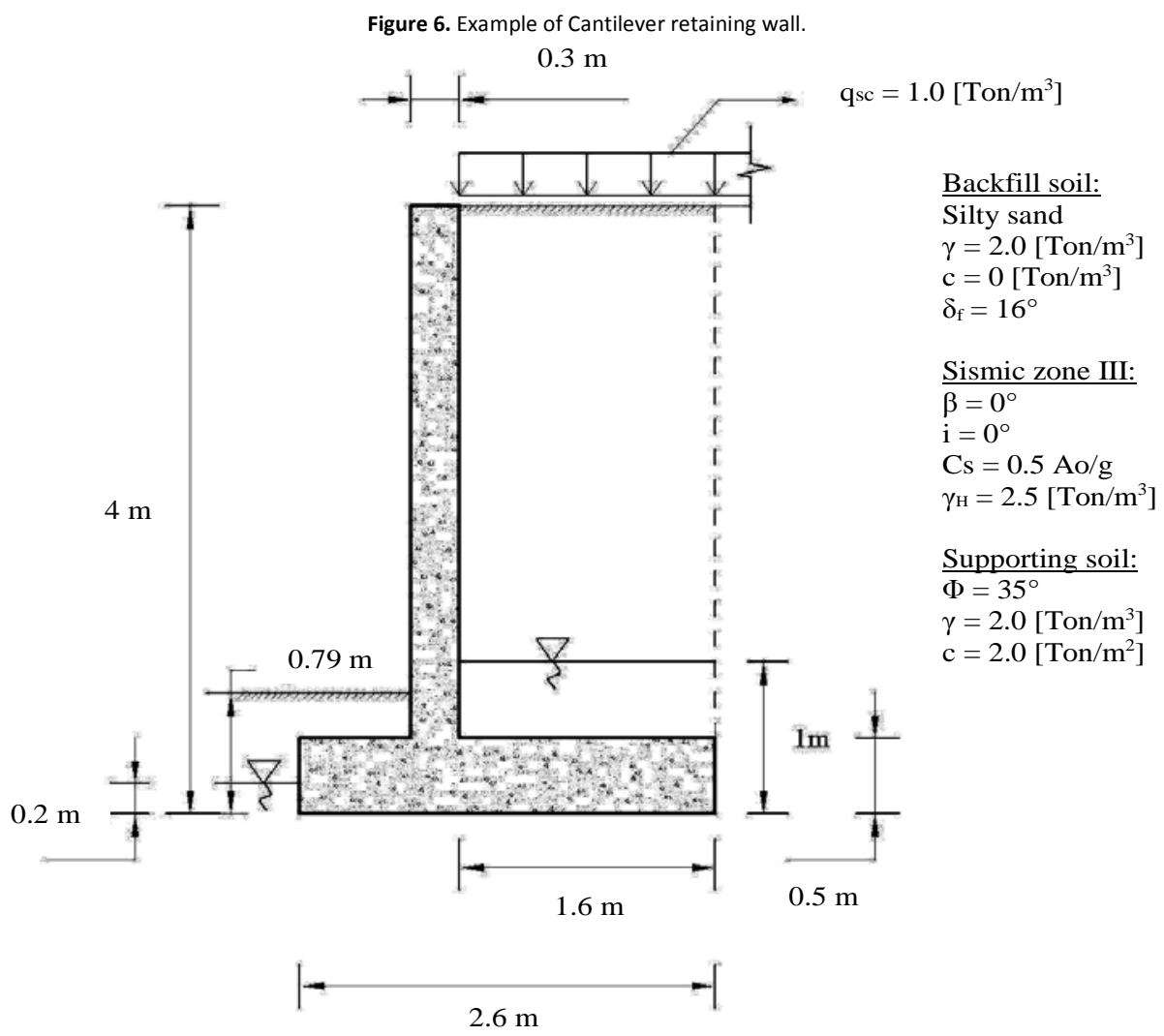

\section{Simulated module considerations}

The following aspects will be considered to be able to use this simulated model in this particular case. Simulation is accomplished according to the grades of compaction (DC\%) corresponding to a silty sand and taking into account the compressing angle as a stochastic variable (simulated variable) and the rest of parameters stay invariable. Three cases are analyzed for the different grades of compaction (GD 80, 90 and 95\%) for normal and lognormal distributions, the best number of runs will reach 10000 repetitions (the optimal run numbers to stabilize the variable outputs or results). For sismic zonation the Chilean regulation NCh 433 of 96" buildings' sismic Design" (INN-Chile, 1993) is used. Where Ee is the static thrust of the filling soil (Ton/ml) and $E s$ is the sismic thrust of the filling soil (Ton/ml) (Table 2-3).

\section{Soil pushes}

Table 2. Average values of filling soil static pushes for different \%DC.

\begin{tabular}{lccc}
\hline & \multicolumn{3}{c}{$\mathrm{E}_{\mathrm{e}}[\mathrm{Ton} / \mathrm{ml}]$} \\
\cline { 2 - 4 } Silty sand & $\mathrm{DC}$ 80\% & DC 90\% & DC 95\% \\
\hline Normal Distribution & 5.529 & 4.835 & 4.326 \\
Lognormal Distribution & 5.563 & 4.883 & 4.340 \\
\hline
\end{tabular}

Table 3. Average values of filling soil sismic pushes for different \% DC.

\begin{tabular}{lccc}
\hline & \multicolumn{3}{c}{$\mathrm{E}_{\mathrm{s}}[\mathrm{Ton} / \mathrm{ml}]$} \\
\cline { 2 - 4 } Silty sand & DC 80\% & DC 90\% & DC 95\% \\
\hline Normal Distribution & 2.253 & 2.075 & 1.943 \\
Lognormal Distribution & 2.262 & 2.087 & 1.946 \\
\hline
\end{tabular}




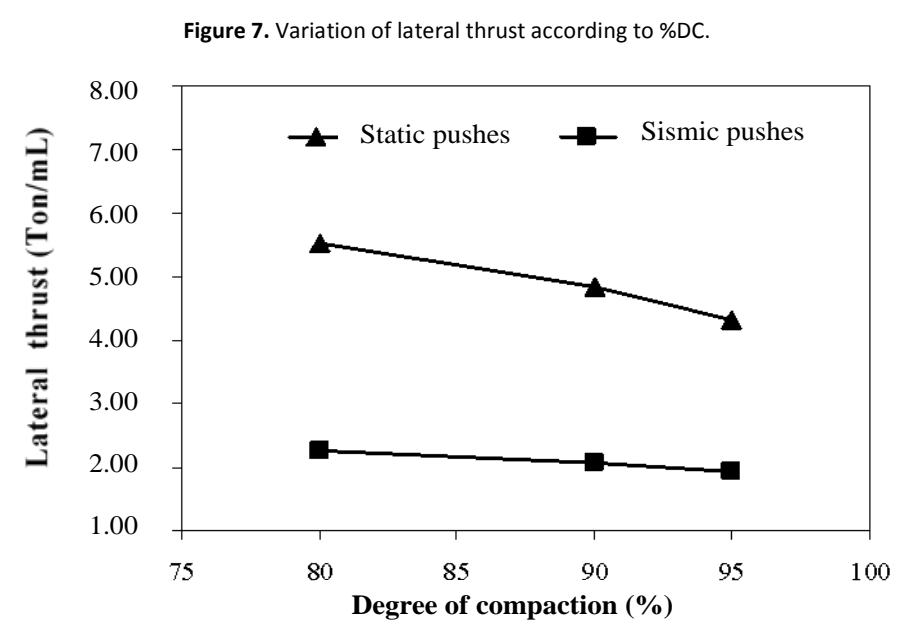

Reliance Factors

Static Analysis

Table 4. Static security factors for different degrees of compaction.

\begin{tabular}{lcccc}
\hline & \multicolumn{4}{c}{ Expected value } \\
\cline { 2 - 5 } Silty sand & FSED & $\sigma$ & FSEV & $\sigma$ \\
\hline DC 80\% & & & & \\
Normal Distribution & 2.168 & 0.202 & 4.387 & 0.484 \\
Lognormal Distribution & 2.174 & 0.130 & 4.401 & 0.153 \\
DC 90\% & & & & \\
Normal Distribution & 2.453 & 0.287 & 5.062 & 0.668 \\
Lognormal Distribution & 2.474 & 0.165 & 5.095 & 0.584 \\
DC 95\% & & & & \\
Normal Distribution & 2.705 & 0.315 & 5.641 & 0.706 \\
Lognormal Distribution & 2.729 & 0.169 & 5.669 & 0.579 \\
\hline
\end{tabular}

\section{Sismic Analysis}

\begin{tabular}{lcccc}
\multicolumn{3}{c}{ Table 5. Sismic security factors for different degrees of compaction. } \\
\cline { 2 - 5 } Silty sand & \multicolumn{4}{c}{ Expected value } \\
\hline DSSD & $\sigma$ & FSSV & $\sigma$ \\
\hline Normal Distribution & 1.108 & 0.067 & 1.618 & 0.110 \\
Lognormal Distribution & 1.107 & 0.085 & 1.617 & 0.095 \\
DC 90\% & & & & \\
Normal Distribution & 1.196 & 0.085 & 1.762 & 0.138 \\
Lognormal Distribution & 1.198 & 0.100 & 1.763 & 0.110 \\
DC 95\% & & & & \\
Normal Distribution & 1.269 & 0.086 & 1.879 & 0.137 \\
Lognormal Distribution & 1.270 & 0.098 & 1.879 & 0.104 \\
\hline
\end{tabular}



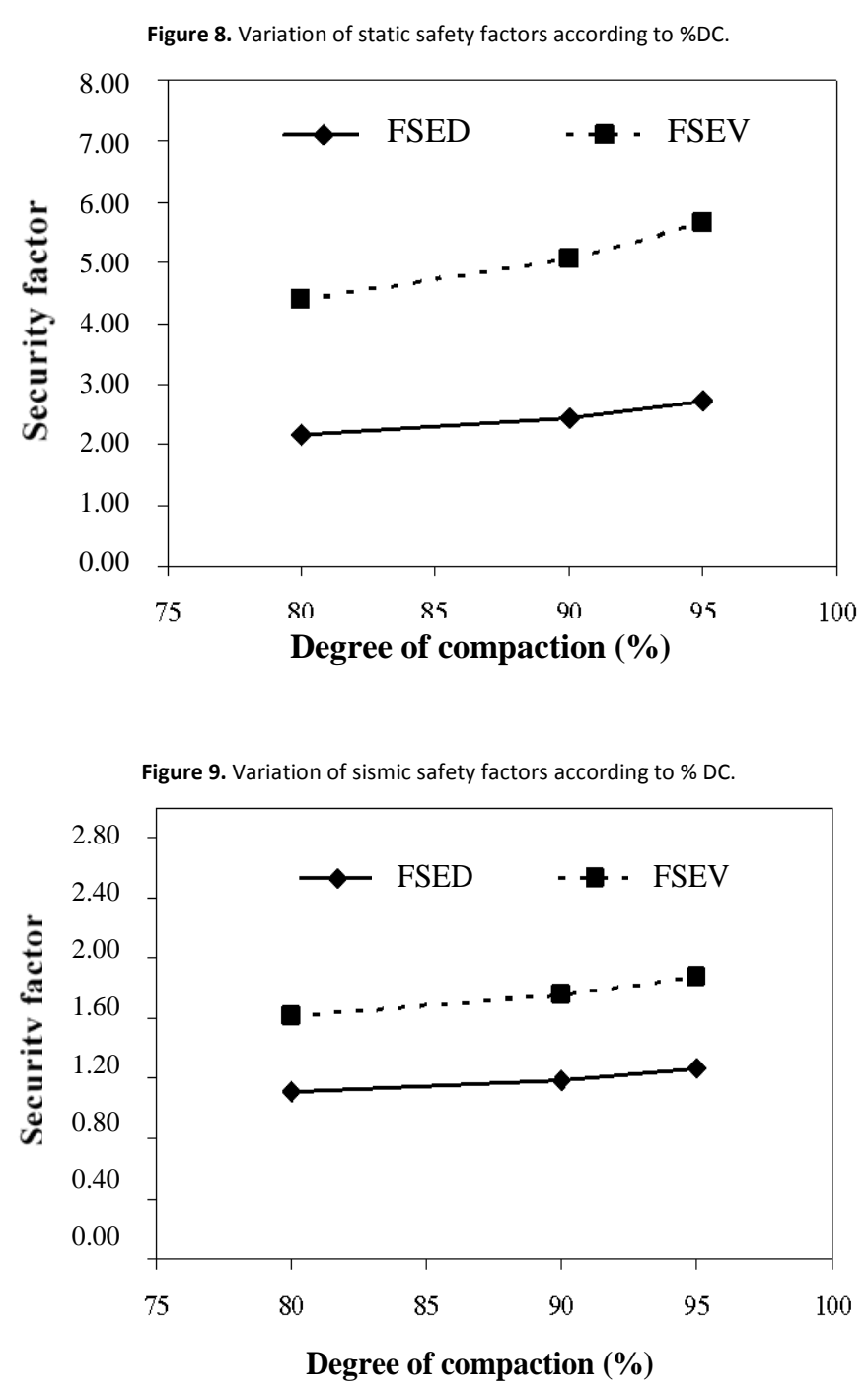

It can be seen from Table 6 to 9 that the variability in safety factors influences under a high risk of seismic failure for slip stability (FSSD), but not for FSED, FSEV and FSSV factors. In Figure 16, this situation is summarized for the compaction degrees analyzed.

\section{Static safety factor when slipping}

\begin{tabular}{lccccc}
\multicolumn{5}{c}{ Table 6. Estimation of PF for FSED under diverse DC\%. } \\
\hline & FSED & $\sigma$ & CV & $\beta$ & PF \\
\hline DC 80\% & & & & & \\
Normal Distribution & 2.168 & 0.202 & 0.093 & -3.31 & $0.00 \%$ \\
Lognormal Distribution & 2.174 & 0.105 & 0.048 & -6.42 & $0.00 \%$ \\
DC 90\% & & & & & \\
Normal Distribution & 2.453 & 0.287 & 0.117 & -3.32 & $0.00 \%$ \\
Lognormal Distribution & 2.474 & 0.165 & 0.067 & -5.90 & $0.00 \%$ \\
DC 95\% & & & & & \\
Normal Distribution & 2.705 & 0.315 & 0.116 & -3.83 & $0.00 \%$ \\
Lognormal Distribution & 2.729 & 0.169 & 0.062 & -7.27 & $0.00 \%$ \\
\hline
\end{tabular}




\begin{tabular}{lccccc}
\multicolumn{5}{c}{ Table 7. Estimation of PF for FSEV under diverse DC\%. } \\
\hline & FSEV & $\sigma$ & CV & $\beta$ & PF \\
\hline DC 80\% & & & & & \\
Normal Distribution & 4.387 & 0.484 & 0.110 & -5.96 & $0.00 \%$ \\
Lognormal Distribution & 4.401 & 0.153 & 0.035 & -18.96 & $0.00 \%$ \\
DC 90\% & & & & & \\
Normal Distribution & 5.062 & 0.668 & 0.132 & -5.33 & $0.00 \%$ \\
Lognormal Distribution & 5.095 & 0.584 & 0.115 & -6.16 & $0.00 \%$ \\
DC 95\% & & & & & \\
Normal Distribution & 5.641 & 0.706 & 0.125 & -5.87 & $0.00 \%$ \\
Lognormal Distribution & 5.669 & 0.579 & 0.102 & -7.20 & $0.00 \%$ \\
\hline
\end{tabular}

\section{Sismic safety factors when slipping}

\begin{tabular}{lccccc}
\multicolumn{5}{c}{ Table 8. Estimation of PF for FSSD under diverse DC\%. } \\
\hline & FSSD & $\sigma$ & CV & $\beta$ & PF \\
\hline DC 80\% & & & & & \\
Normal Distribution & 1.108 & 0.067 & 0.060 & -0.12 & $5.35 \%$ \\
Lognormal Distribution & 1.107 & 0.085 & 0.077 & -0.08 & $10.40 \%$ \\
DC 90\% & & & & & \\
Normal Distribution & 1.196 & 0.085 & 0.071 & -1.13 & $1.06 \%$ \\
Lognormal Distribution & 1.198 & 0.100 & 0.083 & -0.98 & $2.39 \%$ \\
DC 95\% & & & & & \\
Normal Distribution & 1.269 & 0.086 & 0.068 & -1.97 & $0.09 \%$ \\
Lognormal Distribution & 1.270 & 0.098 & 0.077 & -1.73 & $0.29 \%$ \\
\hline
\end{tabular}

\section{Sismic safety factors when overturning}

\begin{tabular}{lccccc}
\multicolumn{5}{c}{ Table 9. Estimation of PF for FSSV under diverse DC\%. } \\
\hline & FSSV & $\sigma$ & CV & $\beta$ & PF \\
\hline $\begin{array}{l}\text { DC 80\% } \\
\text { Normal Distribution }\end{array}$ & 1.618 & 0.110 & 0.068 & -3.13 & $0.00 \%$ \\
Lognormal Distribution & 1.617 & 0.095 & 0.059 & -3.62 & $000 \%$ \\
DC 90\% & & & & & \\
Normal Distribution & 1.762 & 0.138 & 0.078 & -2.80 & $0.00 \%$ \\
Lognormal Distribution & 1.763 & 0.110 & 0.062 & -3.50 & $0.00 \%$ \\
$\begin{array}{l}\text { DC 95\% } \\
\text { Normal Distribution }\end{array}$ & 1.879 & 0.137 & 0.073 & -3.06 & $0.00 \%$ \\
Lognormal Distribution & 1.879 & 0.104 & 0.055 & -4.02 & $0.00 \%$ \\
\hline
\end{tabular}

\section{Reliance Analysis}

The application example shows the way an application influences the angle variability due to an internal compression in a FSSD, although it is higher than 1, this one has a standard deviation between 0.670 and 0.100 , making possible a fail probability from 5.35 to $10.40 \%$ for Normal and lognormal distribution respectively., validating the reliance factor proposed by highroads Manual. Consequently, the design is optimized as well as the wall stability thus, increasing filling soil compression up to DC 95\%, having a fail probability that ranges from 0.09 and $0.29 \%$ for normal and lognormal distributions, respectively. Then wall reliability is calculated by using equation (6) having a reliance of 99.91 and $99.97 \%$ for normal and lognormal distributions. Figure 16 
shows the variation from wall safety due to the filling soil improvement from DC 80 to $95 \%$, the latter case shows no risk of wall fail since the reliance reaches almost $100 \%$.
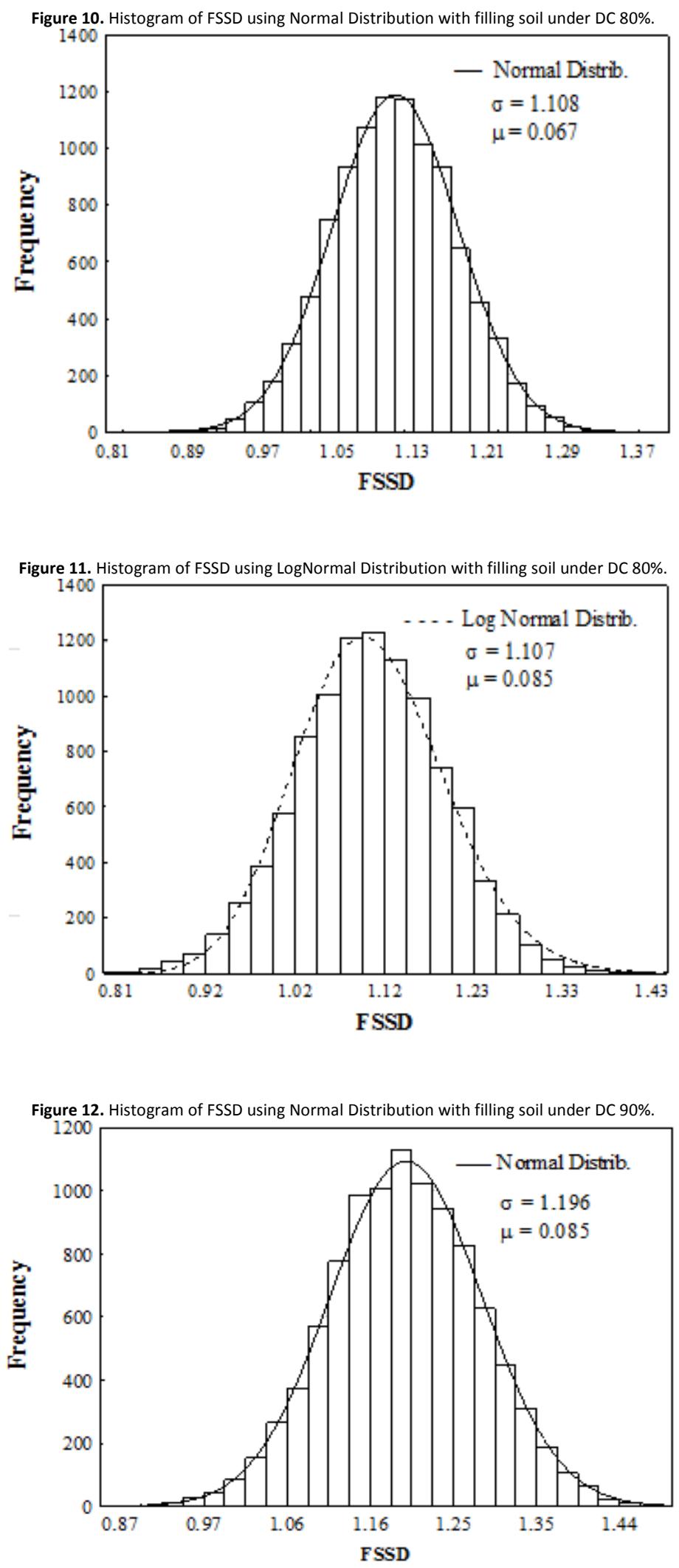
Figure 13. Histogram of FSSD using LogNormal Distribution with filling soil under DC $90 \%$

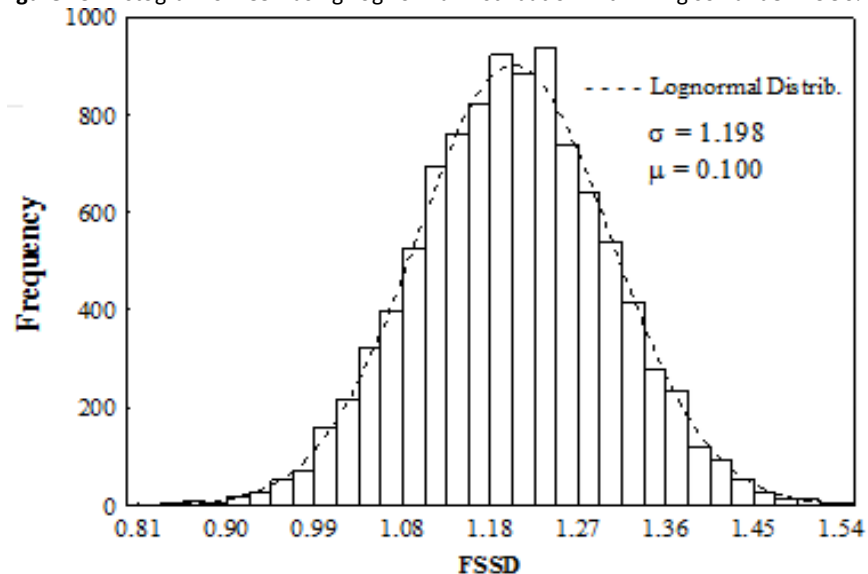

Figure 14. Histogram of FSSD using Normal Distribution with filling soil under DC $95 \%$.

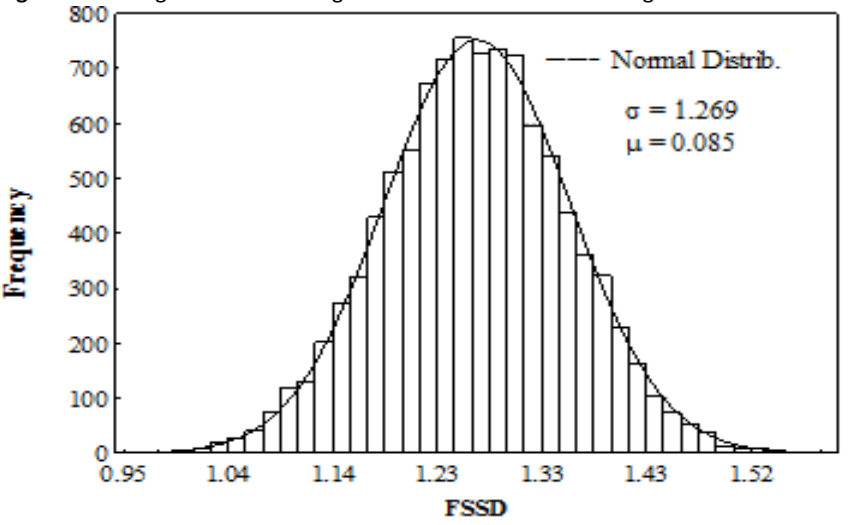

Figure 15. Histogram of FSSD using LogNormal Distribution with filling soil under DC $95 \%$.

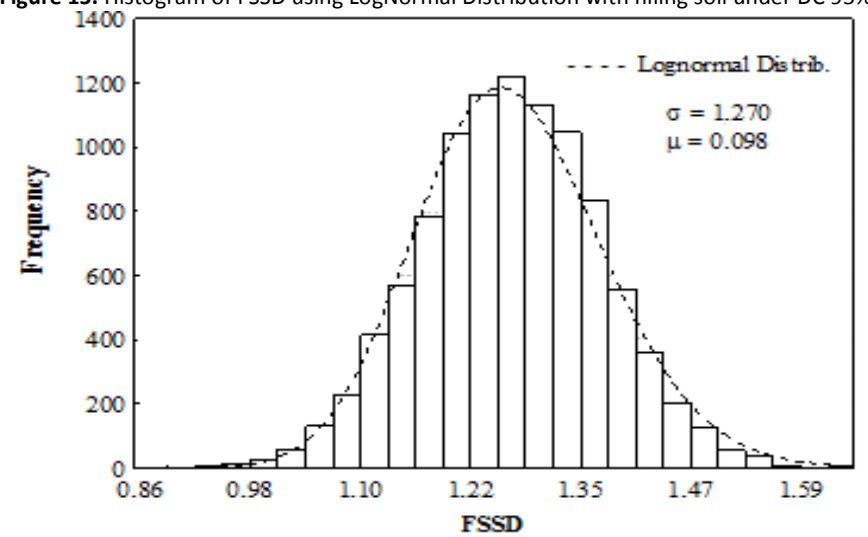


Figure 16. Slip failure probability of sismic case according to \% DC.
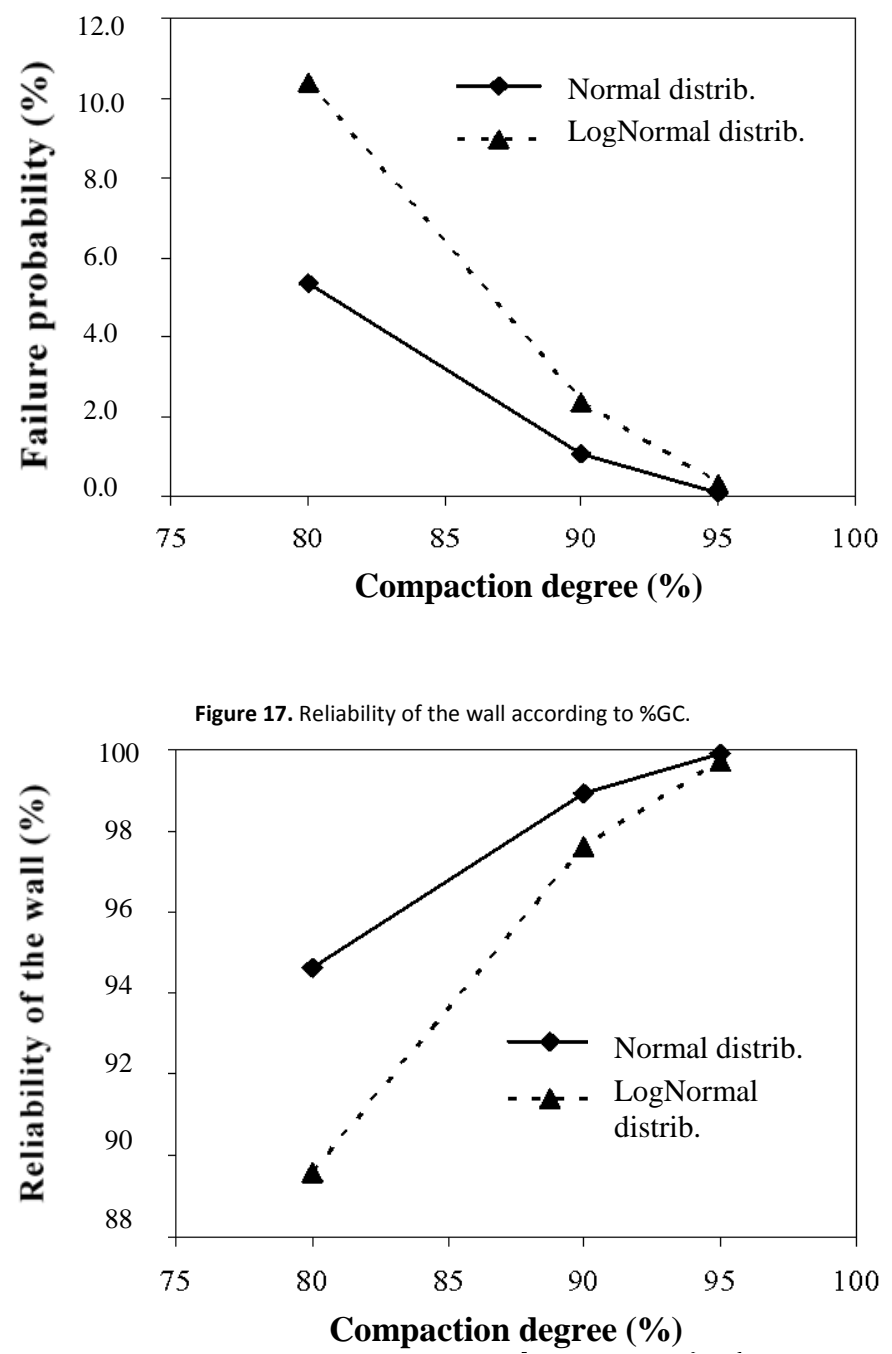

Conclusions

The variability from the parameters inherent to the soil such as the internal compressing angle and density influences soil thrust calculations both static and sismic, therefore, on the retaining wall stability and the internal stress from the retaining wall's structural element. It can be noticed that a compression from the filling increases, the static and sismic thrusts decrease for DC\% ranging from $80-90 \%$ and from $90-95 \%$. The thrust decrease reaches a $13 \%$ in the case of static and a $7 \%$ in the sismic case, respectively. Furthermore, an increase in the filling compression increases the values of compressing angle. Such an increase allows an improvement of wall's safety adding up to $27 \%$ in the static case and $15 \%$ in the sismic case. It is advised to choose internal compressing values and soil density values as nearest as possible to the real parameters since a small change may develop a meaningful variation that could influence the reliance factors from walls. In the example the wall safety was quantified. In case the wall safety is not improved as far as the safety is concerned up to a $100 \%$, it is advised to optimize the wall geometrical design and to perform it by a software dealing with wall analysis to decrease the calculation time.

Acknowledgments

The authors gratefully acknowledge the support provided by Department of Civil Engineering at Universidad de La Serena and Department of Food Science and Chemical Technology at Universidad de Chile. 
Box, G. \& Müller, M. (1958). A Note on the Generation of Random Normal Deviates. The Annals of Mathematical Statistics, 29(2) 610-611.

Calavera, J. (1989). Muros de Contención y Muros de Sótano. 2a Edición, Ed. Instituto Técnico de Materiales y Construcciones.

Calderón, R. (2004). Determinación de Parámetros de Resistencia al Corte en Arenas Limosas y Propuesta de Implementación de Equipo de Compresión Triaxial. Memoria de Título, Departamento de Obras Civiles, Universidad de La Serena, Chile.

Carillo, J. \& Alcocer, S. (2011). Degredation properties of reinforced concrete walls with openings. Revista DYNA, 78(170) 106-115.

Centeno, R. (2002). Simulación de Monte Carlo y su aplicación a la Ingeniería Geotécnica. XVII Seminario Venezolano de Geotecnia, Caracas, Venezuela.

Okabe, S. (1926). General theory of Earth Pressures. Journal Japan Society of Civil Engineering, 12(1).

Dirección de Vialidad. (2008). Manual de Carreteras - Vol. 3: Instrucciones y Criterios de Diseño, Chile.

Elkateb, T. \& Chalaturnyk, R. (2003). An overview of soil heterogeneity: Quantification and implications on geotechnical field problems. Canadian Geotechnical Journal, 40(1) 1-15. https://doi.org/10.1139/t02-090.

García, E., García, H. \& Cárdenas, L. (2006). Simulación y análisis de sistemas con Promodel. 2 Edición. Pearson Educación Prentice Hall, México.

González, J. \& Lemus, L. (2010). Actualización del software de diseño y análisis de muros de contención mediante simulación de Monte Carlo. Memoria de Título de Ingeniería Civil, Departamento de Obras Civiles, Universidad de La Serena, Chile.

INN-Chile. (1996). Norma Chilena NCh 433 Of. 96. Diseño sísmico de edificios. Santiago, Chile: Instituto Nacional de Normalización.

Phoon, K. \& Kulhawy, F. (1999). Characterization of geotechnical variability. Canadian Geotechnical Journal, 36(4), 612-24. https://doi.org/10.1139/t99-038.

Popescu, R., Prevost, J. \& Deodatis, J. (1998). Spatial variability of soil properties: two case studies. Geotechnical Earthquake Engineering and Soil Dynamics. Geotechnical special publication ASCE, 75, 568-579.

Rankine, A. \& Coulomb, C. (1976). Essai sur une Application des Regles de Maximis et Minimun quelques. Problemes de Statique Relatifs à Architecture. Mem Acad. Roy. Des Scences, Paris, 3.

Rodríguez, J. (2006). Apuntes de Clases: Mecánica de suelos y fundaciones. Departamento de Ingeniería Civil, Universidad de La Serena, La Serena, Chile.

Torres, R. (2008). Análisis y Diseño de Muros de Contención de Concreto Armado. 2a Edición, Facultad de Ingeniería de la Universidad de Los Andes, Venezuela.

Vanmarcke, E. (1977). Probabilistic modeling of soil profiles. Journal of the Geotechnical Engineering Division ASCE, 103(GT11), $1227-1246$.

Zevgolis, I. \& Bourdeau, P. (2010). Probabilistic analysis of retaining walls. Computers and Geotechnics, 37(3), $359-373$. https://doi.org/10.1016/j.compgeo.2009.12.003 